\title{
THE INFLUENCE OF SUPRADIAPHRAGMATIC SPLANCH- NICECTOMY ON THE HEART IN HYPERTENSION
}

\author{
Emil M. Isberg, M.D., Miami Beach, Fla., and \\ Max M. Peet, M.D., Ann Arbor, Mich.
}

GURGICAL treatment has been submitted by Peet and Isberg $^{1}$ as a measure $S$ capable of arresting and sometimes reversing, in a significant percentage of cases, the progressive deteriorating course of arterial hypertension. This opinion has been founded on the results of a long-term study of a large group of hypertensive patients treated by splanchnic resection. The operation of bilateral supradiaphragmatic splanchnicectomy and lower dorsal sympathetic ganglionectomy has been performed in more than 1,500 hypertensive patients at the University Hospital since November, 1933.

The purpose of the present study has been to obtain information concerning the cardiac aspects in arterial hypertension and how these have been influenced by surgical treatment. In order that temporary benefits from the operation be eliminated before judgment was passed, the results in only those cases operated upon five to thirteen years ago have been considered.

Studies of surgically treated hypertensive patients have suggested that the operation has influenced the destiny of the heart in hypertension. It was first recognized in 1934 that significant improvement in abnormal electrocardiograms and definite reduction in heart size occurred in some cases following splanchnicectomy. These clinical phenomena were first reported in 1939 by Braden and Kahn, ${ }^{2}$ associates of Peet. In 1940, the results in 350 consccutive, surgically treated cases were evaluated by Peet, Woods, and Braden, ${ }^{3}$ and again it was pointed out that cardiac enlargement and abnormal electrocardiograms were sometimes beneficially improved after operation. Others ${ }^{4,5}$ have recently confirmed the effect of sympathectomy on the electrocardiogram in hypertension.

Each of the foregoing reports dealt with patients who could be followed only for a relatively short period of time. Electrocardiograms and heart size. were reported as improved in cases followed only six months and longer. The present study is concerned entirely with the prolonged effects of splanchnicectomy ; all patien ts have been followed from five to twelve years since operation

\section{MATERIAL}

Between November, 1933, and December, 1941, 720 cases of arterial hyper. tension were surgically treated. The operative procedure consisted of bilateral resection of the greater, lesser, and least splanchnic nerves, and excision of the eighth, ninth, tenth, eleventh, and twelf th thoracic sympathetic ganglia. In

From the Section of Neurosurgery, University of Michigan Medical school and Hospital. Received for publication A pril 25, 1947. 
the early operations, in addition to the splanchnic nerves, only the lower three dorsal ganglia were removed. The operative mortality was 3.2 per cent. During the eight years, 162 cases of malignant hypertension were operated upon, and when these are excluded, the operative mortality for the series is 1.6 per cent.

Adequate preoperative and postoperative information with respect to cardiac status has been obtained in 384 cases. Both an electrocardiogram and teleroentgenogram were procured in each of the 384 patients prior to operation; physical examinations were performed both in the departments of internal medicine and neurosurgery. Thus, a definite diagnosis concerning whether or not organic heart disease complicated the hypertension could be made in each instance. The cases of malignant hypertension, surgically treated during the same years, are not included in this study; the diagnosis of malignanc hypertension was made only in those patients who showed definite papilledema of 1 diopter or more and a recent, rapidly progressive, downhill clinical course. It is felt that malignant hypertension is a distinct disease entity in itself, and a study of this disease will be reported separately. ${ }^{6}$

\section{FINDINGS}

Survival Rates.-Of the 384 cases of arterial hypertension in this series, 257 had definite organic heart disease prior to operation, confirmed by an abnormal electrocardiogram or teleroentgenogram showing cardiac cnlargement or both. Of these patients with hypertensive heart disease, 60 per cent were alive five to twelve years postoperatively (Table I). Of the 127 hypertensive patients with normal hearts, 93 per cent were alive five to twelve years after operation. The five-to-twelve-year survival rate for the entire series of 384 is 71 per cent.

The fifty-nine persons who had sustained a cerebral accident in addition to having hypertensive heart disease prior to operation have a considerably lower survival rate than those with cardiac involvement and no cerebrovascular complication. Only 46 per cent of the former were living after five to twelve postoperative years, while 64 per cent of the latter were living.

Table I. Survival Rates in Three Hundred Eighty-four Cases of Hypertension

\begin{tabular}{l|r|r|r}
\hline \multicolumn{1}{c|}{ PREOPERATIVE STATUS } & CASES & DEATHS & 5-TO-12 YEAR SURVIVALS \\
\hline Normal heart & 127 & 9 & $118(93 \%)$ \\
\hline Organic heart disease & 198 & 71 & $127(64 \%)$ \\
\hline Heart disease plus cerebrovascular disease & 59 & 32 & $27(46 \%)$ \\
\hline Totals & 384 & 112 & $272(71 \%)$ \\
\hline
\end{tabular}

The Electrocardiogram.-An electrocardiogram was considered abnormal only when one or more of the following findings was present: (1) definite left 
axis deviation ( $R_{1}+S_{s}=25 \mathrm{~mm}$. or more); (2) inversion of $\mathrm{T}$ waves in Lead 1 . in Leads I and II, or in Leads II and III; (3) bundle branch block; and (4) evidences of previous myocardial infarction.

An abnormal electrocardiogram was considered "significantly improved" hive years and more after operation only when: (1) inverted $T$ waves returned to an upright configuration with an amplitude of $1 \mathrm{~mm}$. or more, or (2) $30^{\circ}$ change of electrical axis loward normal occurred with reduction of $8 \mathrm{~mm}$. or more in the value of $R_{1}+S_{3}$. An electrocardiogram with both abnormal $T$ waves and left axis deviation was considered "improved" when either one of these criteria was fulfilled.

A postoperative electrocardiogram was considered to be "worse" when any one of the following appeared: (1) $1 \mathrm{~mm}$. or more depression of a previously upright or flat $\mathrm{T}$ wave in Lead $\mathrm{I}$ or $\mathrm{II}$; (2) a $30^{\circ}$ change of electrical axis toward abnormal, with increase of $8 \mathrm{~mm}$. or more in the value of $R_{1}+S_{3}$; (3) evidences of myocardial infarction; and (4) bundle branch block.

Two hundred nineteen patients had abnormal preoperative electrocardiograms; 60 per cent of these persons were still living five to twelve years postoperatively. Of the 165 hypertensive patients with normal electrocardiograms. 85.5 per cent were alive five years and more after operation.

Table II enumerates the incidence of the various electrocardiographic abnormalities in this series, the subsequent deaths with each abnormality, and the electrocardiographic status of the living patients five years and more after operation. It is seen that patients with inverted $T$ waves in both Leads I and II have the highest death rate; but when these patients survive five years and more their tracings are likely to be "significantly improved."

One hundred eighty-four living patients had recent elcctrocardiograms taken, five to twelve years after operation (Table III). Of the eighty-three who had abnormal tracings prior to operation, 41 per cent now show "significant improvement," 55.4 per cent show no change, and 3.6 per cent have progressed to worse changes. All patients who had sustained a coronary occlusion or were ever given digitalis were automatically excluded from the "significantly improved" classification.

Of the 101 patients whose electrocardiograms were normal preoperatively. 94 per cent have maintained an unchanged, normal tracing during the long postoperative period; in 6 per cent the tracing have become abnormal. Six serjes of electrocardiograms are shown in Figs. 1, 2, 3, 4, 5, and 6 . All were abnormal before operation and improved notably after operation.

There is a definite correlation between postoperative improvement in the electrocardiogram and postoperative reduction in blood pressure. Of the thirtyfour patients who had an abnormal preoperative electrocardiogram and who have maintained a "significantly improved" tracing for five years and more after operation, six have maintained normal blood pressure levels (140/90 or less), 
and twenty-six have maintained a significant reduction of $15 \mathrm{~mm}$. or more diastolic pressure during the postoperative period. Only two patients with improved electrocardiograms showed no improvement in diastolic pressure (Table IV).

Table II. The Electrocardiogram in Three Hundred Eightry-four Hypertensive Patients

\begin{tabular}{|c|c|c|c|c|c|c|c|}
\hline \multirow[b]{2}{*}{ PREOPERATIVE STATUS } & \multirow[b]{2}{*}{ CASES } & \multirow[b]{2}{*}{ DEATHS } & \multicolumn{5}{|c|}{$\begin{array}{c}\text { PATIENTS ALIVE FIVE TO TWELVE } \\
\text { YEARS POSTOPERATIVELY }\end{array}$} \\
\hline & & & $\begin{array}{l}\text { CASES } \\
\text { LIVING }\end{array}$ & $\begin{array}{c}\text { SIGNIFICANT } \\
\text { IMPROVE- } \\
\text { MENT IN ECG }\end{array}$ & $\begin{array}{c}\text { NO SIG- } \\
\text { NIFICANT } \\
\text { CHANGE }\end{array}$ & WORSE & $\begin{array}{l}\text { NO FOL- } \\
\text { LOW-UP } \\
\cdot \text { ECG }\end{array}$ \\
\hline Normal ECG & 165 & 24 & 141 & $\longrightarrow$ & 95 & 6 & 40 \\
\hline Abnormal ECG & 219 & 88 & 131 & 34 & 46 & 3 & 48 \\
\hline Inverted $T_{1}$ & 18 & 6 & 12 & 4 & 3 & 0 & 5 \\
\hline Inverted $T_{1}$ and $T_{2}$ & 54 & 27 & 27 & 13 & 4 & 0 & 10 \\
\hline Inverted $T_{2}$ and $T_{3}$ & 14 & 3 & 11 & 2 & 3 & 1 & 5 \\
\hline Definite L.A.D. & 42 & 10 & 32 & 2 & 18 & 2 & 10 \\
\hline $\begin{array}{l}\text { Both inverted } T \\
\text { waves and definite } \\
\text { L.A.D. }\end{array}$ & 75 & 37 & 38 & 13 & 9 & 0 & 16 \\
\hline Bundle branch block & 5 & 2 & 3 & 0 & 3 & 0 & 0 \\
\hline $\begin{array}{l}\text { Evidences of pre } \\
\text { vious myocardial } \\
\text { infarction }\end{array}$ & 11 & 3 & 8 & 0 & 6 & 0 & 2 \\
\hline
\end{tabular}

Table III. The Influence of Surgical Treatment on tuie Electrocardiograms of One Hundred Eighty-four Patients Five to Twelve Years After Operation

\begin{tabular}{l|l|c|c|c}
$\begin{array}{c}\text { PREOPERATIVE } \\
\text { STATUS }\end{array}$ & CASES & $\begin{array}{c}\text { SIGNIFICANTLY } \\
\text { IMPROVED }\end{array}$ & $\begin{array}{c}\text { NO SIGNIFICANT } \\
\text { CHANGE }\end{array}$ & WORSE \\
\hline Normal ECG & 101 & 83 & $95(94 \%)$ & $6(6 \%)$ \\
\hline Abnormal ECG & $83(41 \%)$ & $46(55.4 \%)$ & $3(3.6 \%)$ \\
\hline
\end{tabular}

None of the electrocardiographic abnormalities which occurred in this series can be considered a contraindication to surgical treatment. The death rate in the presence of any one of the abnormalities is not so great as to render 

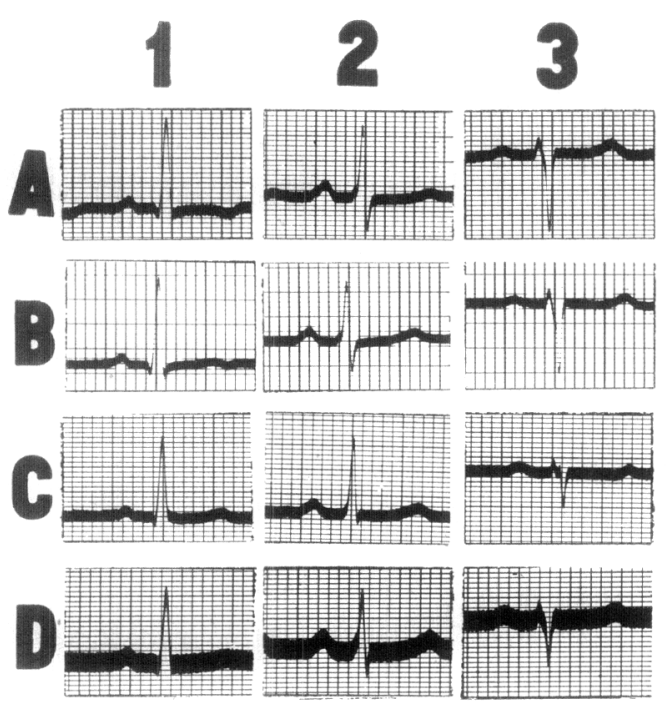

Fig. 1,-Case 1. A, (April 11, 1939) preoperative $\mathrm{ECG}$; left axis deviation and inverted $T$ waves in Lead I. Splanchnicectomy was performed on A pril 15, 1939. $B$, (Oct. 18, 1939) six months postoperative; $T$ waves in Lead I are now upright. C, May 9, 1940. D, (April 13, 1944) five years postoperative; upright $T$ waves maintained in Lead $I$, and left axis deviation is less marked than in preoperative tracing.

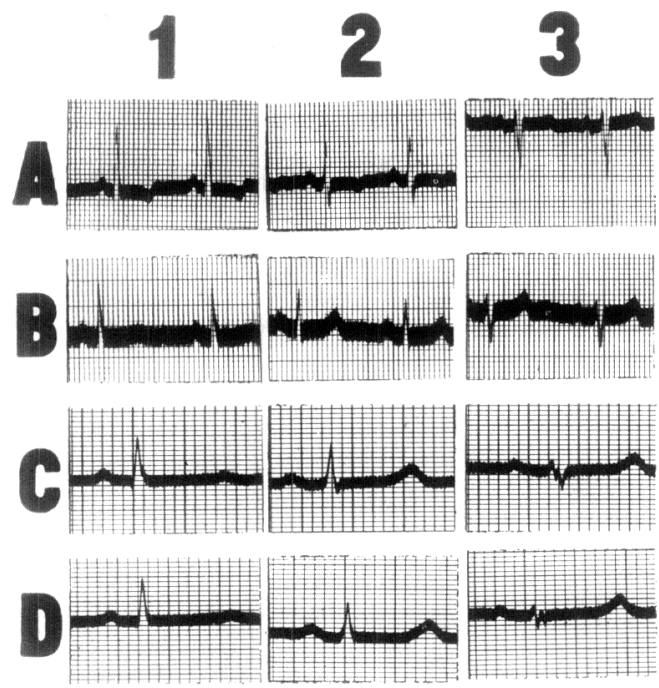

Fig. 3.-Case 3. A, (Nov. 22, 1934) preoperative ECG; definite left axis deviation and inverted $T$ waves in Lead I. Splanchnicectomy was performed on Dec. 3 , 1934. $B$, (Sept. 28, 1937) three years postoperativo; slight left axis doviation and upright $T$ waves in Lead I. C, Aug. 25, 1938. D, (Aug. 27, 1940) six years postoperative; normal ECG. The Q-T interval of the last two tracings is not abnormally long when compared to the heart rate which was 58 per minute.

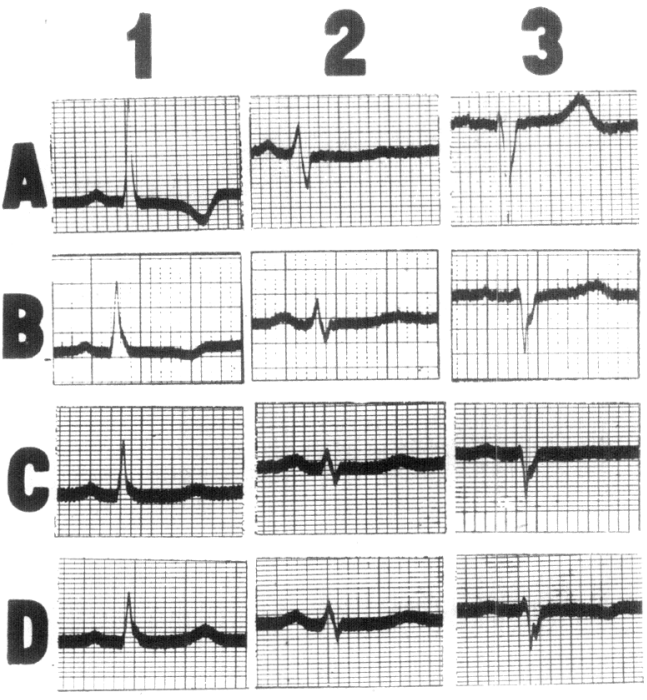

Fig. 2.-Case 2. A, (Oct. 18, 1940) preoperative ECG: definite left axis deviation, inverted $T$ waves in Lead $I$, and flat $T$ waves in Lead II. Splanchnicectomy was performed on Oct. 24, 1940, $B$, (A pril 3, 1941) six months postoperative; $T$ waves in Lead I are less deeply inverted than previously. $C$, (Sept. 1, 1944) four years postoperative; shows almost complete retrogression of the 1940 ECG changes; $T$ waves are now normal and the slight axis deviation is within normal limits. $D$, (Sept. 27, 1945) five years postoperative ist re mains within normal limits.

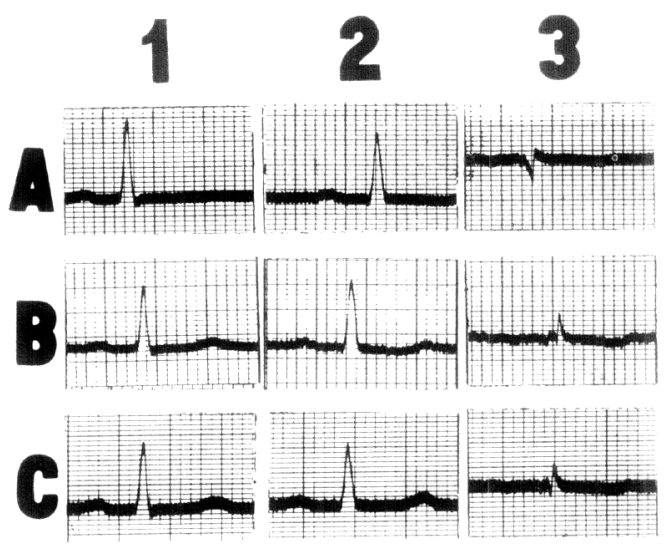

Fig. 4.-Case 4. A, (April 2, 1940) preoperative ECG; flat $T$ waves in Lead $I$ and slight inversion of $T$ waves in Leads II and III. splanchnicectomy was performed on April 11, 1940. B, (Nox. 6. 1940) six months postoperative; slight inversion of $T$ waves in Leads II and III. C, (July 26, 194.5) five years postoperative; normal ECG. 


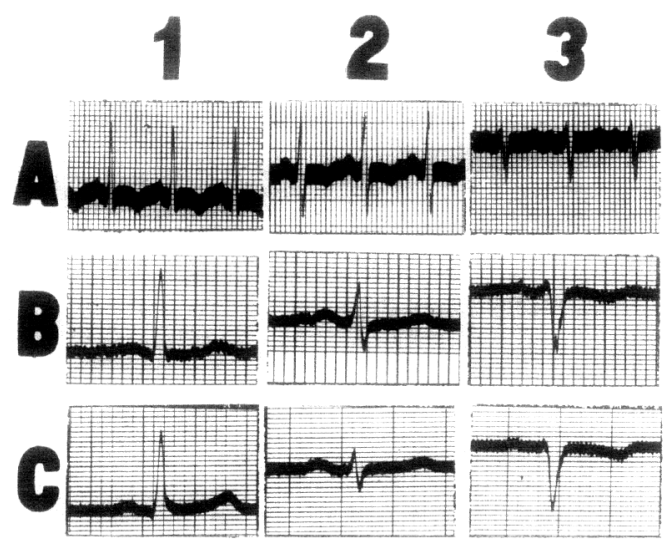

Fig. 5.-Case 5. A, (March 1, 1937) preoperative ECG; left axis deviation and inverled ' $T$ waves iu Leads I and II. Splanchnicectomy was performed on March 6, 1937. $B$, (Sept. 8, 1938) eighteen months postoperative; $\mathrm{T}$ waves are now normal, $C$, (Aug. 7, 1946) normal $T$ waves have been maintained for nine years since operation.

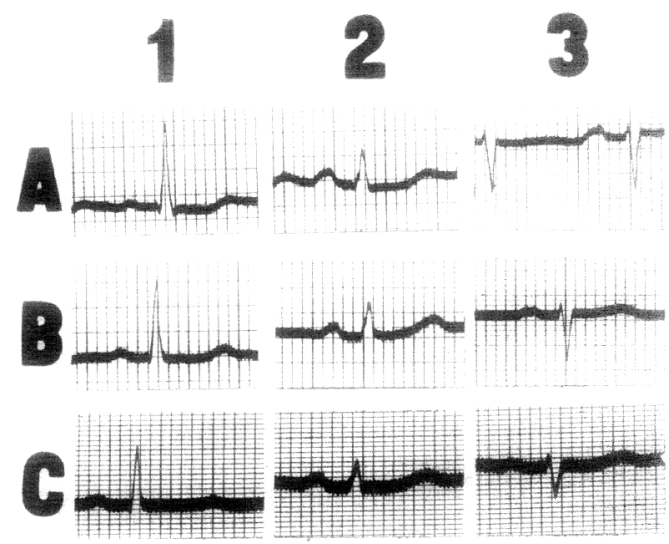

Fig. 6.-Case 6. A, (Aug, 4, 1938) preoperative ECG; delnile lefl axis deviation with depressed $R S-T$ segments and inverted $T$ waves in Leads $I$ and II. Splanchnicectomy was performed on Aug. 18, 1938 . $B$, (April 11, 1939) eight months postoperative; T waves are now upright in Leads I and II. C, (Aug. 9, 1946) eight years postoperative; ECG is within normal limits; $T$ waves are upright and axis deviation is no longer outside normal limits.

splanchnic resection futile, and each of the abnormalities, except bundle branch block and previous myocardial infarction, potentially may be significantly improved following operation.

Heart Sizs.-Heart size in this series has been followed by serial teleroentgenograms taken before and after splanchnic resection. The prediction tables of Hodges, P. C., and Eyster ${ }^{7}$ for frontal area, and the prediction tables of Hodges, F. J., and Eyster ${ }^{\mathbf{8}}$ for transverse diameter have been used. Table V lists the criteria for determining relative extent of cardiac enlargement on the basis of the per cent variation from predicted normal.

Table IV. Correlation of Postoperative Ecg Change With Postoperative Blood Pres sure Change in Eighty-three Patients Who Had Abnormal Ecg Preoperatively

\begin{tabular}{|c|c|c|c|c|}
\hline \multirow[b]{2}{*}{$\begin{array}{c}\text { POSTOPERATIVE } \\
\text { ECG }\end{array}$} & \multirow[b]{2}{*}{ CASES } & \multicolumn{3}{|c|}{ POSTOPERATIVE BLOOD PRESSURE } \\
\hline & & $\begin{array}{l}\text { REDUCED TO } \\
\text { NORMAL }\end{array}$ & $\begin{array}{l}15 \text { MM. OR MORE } \\
\text { REDUCTION IN } \\
\text { DIASTOLIC } \\
\text { PRESSURE }\end{array}$ & $\begin{array}{c}\text { NO CHANGE OR } \\
\text { WORSE }\end{array}$ \\
\hline $\begin{array}{l}\text { Significant improve- } \\
\text { ment }\end{array}$ & 34 & 6 & 26 & 2 \\
\hline No significant change & 46 & 2 & 28 & 16 \\
\hline Worse & 3 & 0 & 0 & 3 \\
\hline
\end{tabular}


In order for a postoperative teleroentgenogram to be considered as demonstrating "significant decrease" in heart size from the preoperative state, there must have occurred a 10 per cent or more decrease in frontal area or transverse diameter variation and change to the next category toward normal, according to Table V. The criterion for "significant increase" is that a 10 per cent or mort increase in frontal area or transverse diameter variation has occurred.

Table V. Crithria for Determining Extent of Cardiac Enlargement

\begin{tabular}{|c|c|c|}
\hline \multirow{3}{*}{ HEART SIZE } & \multicolumn{2}{|c|}{ VARIATION FROM PREDICTED NORMAI. } \\
\hline & & \\
\hline & CARDIAC AREA & TRANSVERSE DIAMETLR \\
\hline Cpper limit of normal & $+10 \%$ & $+10 \%$ \\
\hline Slight cardiac enlargement & $11 \%$ to $20 \%$ & $11 \%$ to $20 \%$ \\
\hline Moderate cardiac enlargement & $21 \%$ to $50 \%$ & $21 \%$ to $50 \%$ \\
\hline Marked cardiac enlargement & Greater than $50 \%$ & Greater than $50 \%$ \\
\hline
\end{tabular}

Cardiac enlargement was present in 177 cases, or 43 per cent of the series. Of the hypertensive subjects in whom an enlarged heart was demonstrated. 50 per cent did not survive five to twelve years after the operation. It is seen that in hypertensive heart disease, patients with cardiac enlargement have a somewhat poorer prognosis than those with an abnormal electrocardiogram. Of those with normal sized hearts, 88.4 per cent were living (Table V1).

Table VI. Heart Size in Three Hundred Eighty-four Hypertinsive Patients

\begin{tabular}{|c|c|c|c|c|c|c|c|}
\hline \multirow[b]{2}{*}{$\begin{array}{l}\text { PREOPERATIVE } \\
\text { STATUS }\end{array}$} & \multirow[b]{2}{*}{ CASES } & \multirow[b]{2}{*}{ DEATHS } & \multicolumn{5}{|c|}{ PATIENTS ALIYE, 5 TO 12 YEARS POSTOPERATWHLY } \\
\hline & & & $\begin{array}{l}\text { CASES } \\
\text { LIVING }\end{array}$ & $\begin{array}{l}\text { SIGNIFICANT } \\
\text { DECREASE IN } \\
\text { HEART SIZE }\end{array}$ & $\begin{array}{c}\text { NO } \\
\text { CHANGE }\end{array}$ & $\begin{array}{l}\text { INCREASE } \\
\text { IN AEART } \\
\text { SIZE }\end{array}$ & $\begin{array}{l}\text { MO } \\
\text { FOLLOW-LY' } \\
\text { TELEROEN'S } \\
\text { GENOGRAK }\end{array}$ \\
\hline Normal heart size & 207 & 24 & 183 & - & 123 & 10 & 50 \\
\hline $\begin{array}{l}\text { Cardiac enlarge- } \\
\text { ment }\end{array}$ & 177 & 88 & 89 & 25 & 26 & 6 & 32 \\
\hline $\begin{array}{l}\text { Slight cardiac } \\
\text { enlargement }\end{array}$ & 83 & 33 & 50 & 11 & 16 & 5 & 18 \\
\hline $\begin{array}{l}\text { Moderate cardiac } \\
\text { enlargement }\end{array}$ & 76 & 38 & 38 & 14 & 10 & 1 & 13 \\
\hline $\begin{array}{c}\text { Marked cardiac } \\
\text { enlargement }\end{array}$ & 18 & 17 & 1 & $\cdots$ & 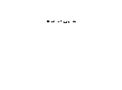 & $\cdots$ & 1 \\
\hline
\end{tabular}


Teleroentgenograms were recently obtained in 190 living patients five to twelve years after operation. Of the fifty-seven patients with preoperative cardiac enlargement, significant decrease in heart size was demonstrated in 44 per cent, 45.6 per cent showed no change, and in 10.4 per cent, further increase in size had occurred (Table VII). Serial teleroentgenograms of four patients whose heart size decreased significantly after operation are shown in Figs. 7, 8, 9, and 10.

Table VII. The Influence of Surgical Treatment on Heart Size, Measured on TeleROENTGENOGRaMS OF ONE HUNDRED NiNETy PATIENTS FIVE TO TWELVE YEARS AfTER Operation

\begin{tabular}{l|c|c|c|c}
\hline & \multicolumn{3}{|c}{ POSTOPERATIVE STATUS } \\
\cline { 2 - 5 } PREOPERATIVE STATUS & CASES & $\begin{array}{c}\text { SIGNIFICANT } \\
\text { DECREASE IN } \\
\text { HEART SIZE }\end{array}$ & NO CHANGE & $\begin{array}{c}\text { SIGNIFICANT } \\
\text { INCREASE IN } \\
\text { HEART SIZE }\end{array}$ \\
\hline Normal heart size & 133 & $25(44 \%)$ & $26(45.6 \%)$ & $6(10.4 \%)$ \\
\hline Cardiac enlargement & 57 & $23(92.5 \%)$ & $10(7.5 \%)$ \\
\hline
\end{tabular}

Of the 133 patients with normal heart size prior to operation, 92.5 per cent maintained an unchanged normal status for five years and more. Cardiac enlargement occurred during the long postoperative period in 7.5 per cent of those who had hearts of normal size before splanchnic resection.

It appears that reduction in blood pressure is necessary in order for a significant decrease in heart size to occur. In all twenty-six persons in whom definite decrease in heart size was demonstrated, blood pressure levels have either been reduced to within normal range, or a significant reduction of $15 \mathrm{~mm}$. or more in diastolic pressure has been maintained (Table VIII).

Table VIII. Correlation of Postoperative Heart Size Change With Postoperative Blood Pressure Change in Fifty-seven Patients Who Had

Preoperative Cardiac Enlargement

\begin{tabular}{|c|c|c|c|c|}
\hline \multirow[b]{2}{*}{ POSTOPERATIVE HEART SIZE } & \multirow[b]{2}{*}{ CASES } & \multicolumn{3}{|c|}{ POSTOPERATIVE BLOOD PRESSURE } \\
\hline & & $\begin{array}{l}\text { REDUCED TO } \\
\text { NORMAL }\end{array}$ & $\begin{array}{c}15 \text { MM. OR MORE } \\
\text { REDUCTION IN } \\
\text { DIASTOLIC PRESSURE }\end{array}$ & $\begin{array}{c}\text { NO CHANGE OR } \\
\text { WORSE }\end{array}$ \\
\hline Significant decrease in size & 25 & 5 & 20 & 0 \\
\hline No change & 26 & 1 & 15 & 10 \\
\hline Increase in heart size & 6 & 0 & 1 & 5 \\
\hline
\end{tabular}



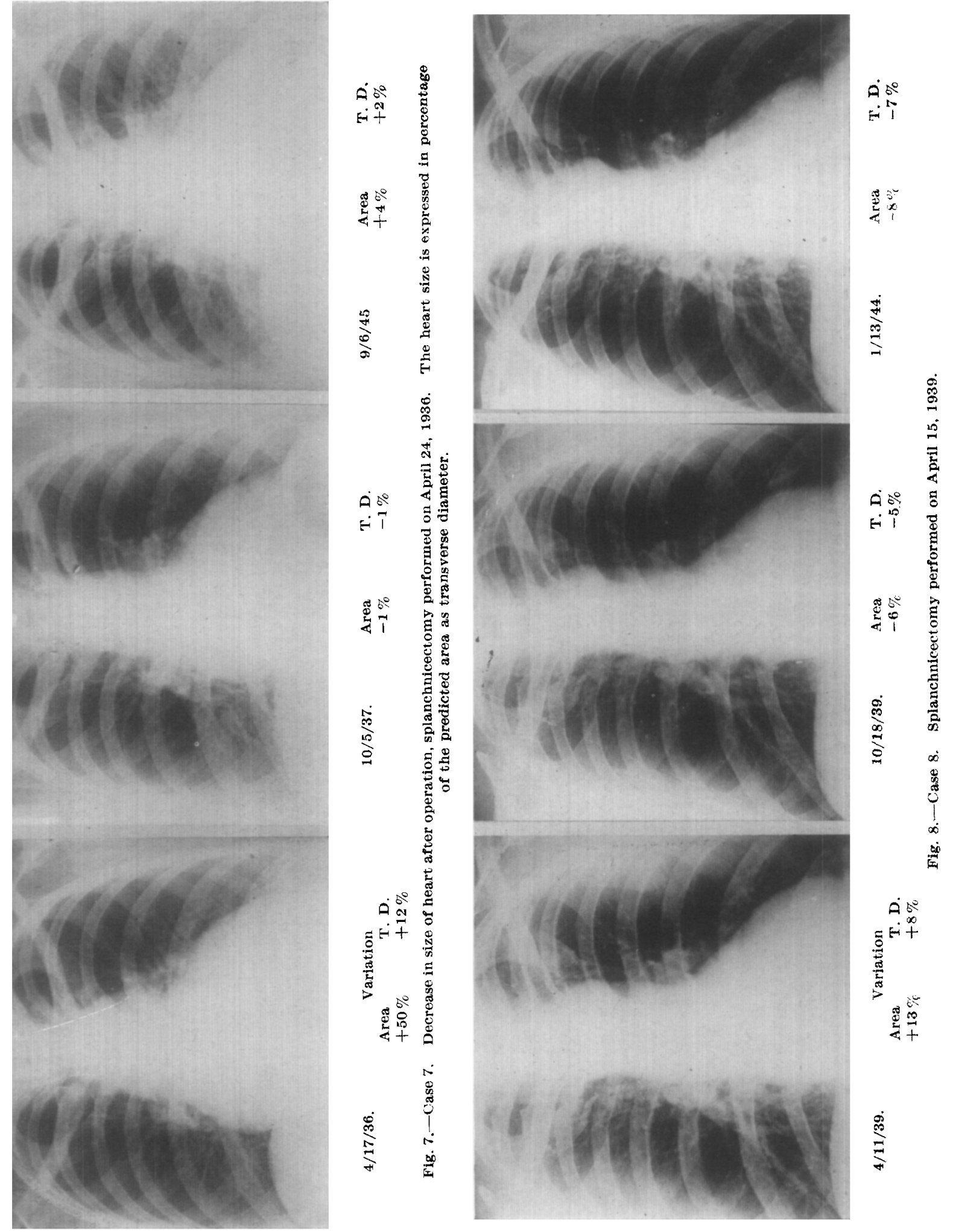


Splanchnic resection has nothing to offer the hypertensive patient with marked cardiac enlargement. When the variation above the predicted normal is greater than 50 per cent for area or transverse diameter, the outlook is grave, and it cannot be influenced by splanchnicectomy. Of the eighteen patients whi had marked cardiac enlargement, only one has survived five years.

Cardiac Symptoms.-One of more of the cardiac symptoms of exertional dyspnea, paroxysmal nocturnal dyspnea, palpitation, swollen ankles, and anginal seizures were present in 54 per cent of the series. Eighty-five per cent of the patients complaining of cardiac symptoms had definite organic heart disease, confirmed by an abnormal electrocardiogram, by a teleroentgenogram showing cardiac enlargement, or by both.

Of 162 patients who complained of exertional dyspnea, 100 had definitely enlarged hearts. Of the patients with exertional dyspnea, 38.3 per cent did not have cardiac enlargement (Table IX).

Fifty-nine per cent of the patients with cardiac complaints have survived five to twelve postoperative years. Of the 124 persons who had preoperative symptoms and who were still living, 60 per cent were improved, 37 per cent have obtained no relief, and 3 per cent were worse.

The patient with paroxysmal nocturnal dyspnea has very little to gain from surgical treatment of his hypertension. There were twenty-four cases with this complaint, and only three survived five years or more. Each of the twentyfour cases had an abnormal electrocardiogram and all but one also had cardiac enlargement.

Sixty-eight patients complained of characteristic anginal seizures, and 84 per cent of these had organic heart disease, confirmed by abnormal electrocardiogram or cardiac enlargement by teleroentgenogram or both. Sixty-two per cent of the patients with angina survived five to twelve years, and more than one-half of those still living have obtained definite relief from the seizures. Fourteen fatients have been completely relieved of angina for five years or more since splanchnic resection.

Of the 174 hypertensives who had no cardiac complaints, 85 per cent are still living. Ninety-three per cent still have no cardiac symptoms, while 7 per cent have developed symptoms during the long postoperative periorl.

Physical Signs.-Abnormal cardiac physical signs were present in 160 patients, or 24 per cent of the series, and 84 per cent of these had confirmed organic heart disease (Table $\mathbf{X}$ ).

Fifty-eight per cent of patients with a systolic murmur and 60.6 per cent of patients with an accentuated aortic second sound were living five to twelve years after operation. This approximates the overall 60 per cent survival rate of the group with hypertensive heart disease.

Only 23.3 per cent of the patients with gallop rhythm and 33.2 per cent of those with an accentuated pulmonic second sound have lived five to twelve years 







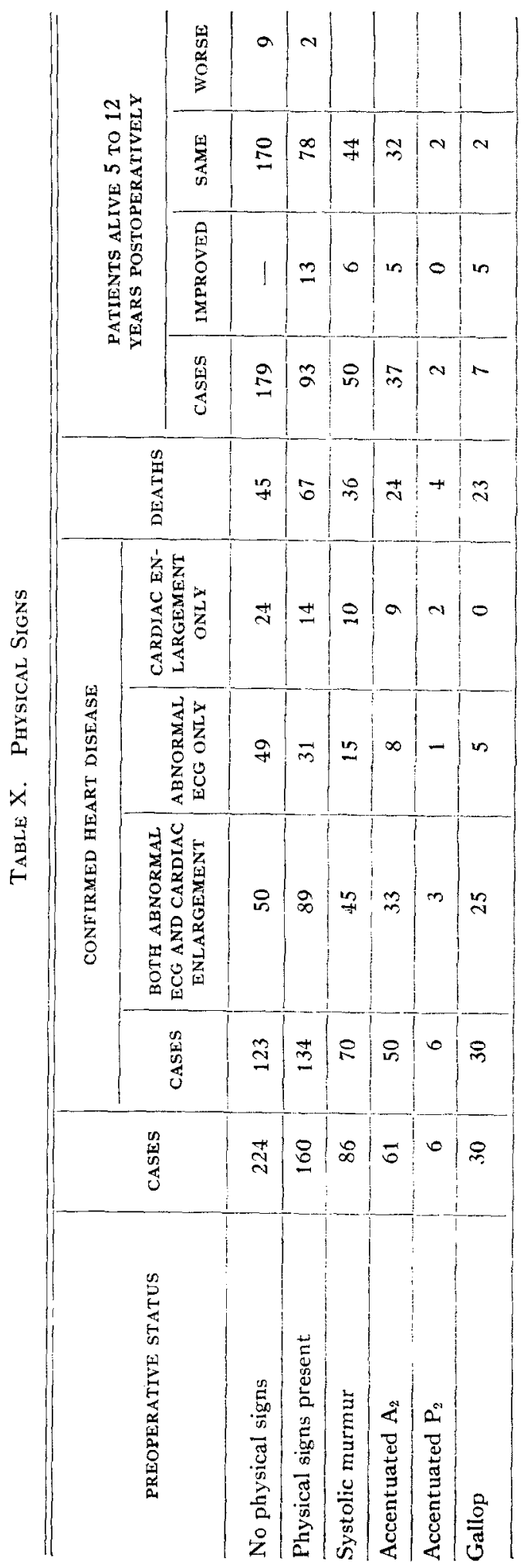


following operation. Although splanchnic resection offers only a slim chance for prolonged survival to these patients, the presence of either one of these two signs does not contraindicate operation.

Congestive Heart Failure.-Sixteen patients in congestive heart failure were digitalized prior to splanchnicectomy. Only five of these patients were living after five years or more. One patient died on the day following operation.

The hypertensive cardiac patient who requires digitalization has a grave outlook. But since such a patient stands one chance in three for prolonged survival following splanchnic resection, he should not be denied the oferation once he is properly digitalized.

Coronary Occlusion.--Eleven patients who had had a coronary occlusion with myocardial infarction were subsequently treated by splanchnicectomy for their hypertensive disease. Eight of these persons were still living five to nine years after operation. The three deaths each resulted from a subsequent coronary occlusion, one to four years after operation.

This prolonged survival of 72.7 per cent of the hypertensive patients who had also had a coronary occlusion should lead one to consider seriously splanchnicectomy in hypertensive patients six to twelve months following a coronary occlusion.

Coronary occlusion has occurred in twenty-four patients out of the entire series from three months to eleven months after operation. Six have survived myocardial infarction, and were still living five to ten years after splanchnic resection. It has been the cause of death in eighteen cases; 17 per cent of th 112 deaths in this series have resulted from coronary occlusion. Goldring and Chasis ${ }^{9}$ have compiled the causes of death in patients with hypertensive disease as reported by various authors, and coronary thrombosis accounted for 13.6 per cent of the total deaths in six different series.

Of the twenty-four cases who sustained a coronary occlusion subsequent to splanchnicectomy, twenty had both an abnormal electrocardiogram and cardiac enlargement before operation. Five had anginal seizures preoperatively, and in four patients gallop rhythm was present prior to splanchnic resection.

\section{DISCUSSION}

The study of cardiac aspects in 384 cases of arterial hypertension treated by splanchnic resection five to thirteen years ago have revealed the following:

1. Sixty per cent of patients with hypertensive heart disease were still living five to twelve years after splanchnicectomy.

2. Ninety-three per cent of hypertensive patients with normal hearts were still living five to twelve years after operation.

3. Patients whose electrocardiograms show inverted $T$ waves in both Leads I and II, or both definite left axis deviation and abnormal $\mathrm{T}$ waves, have a 50 per cent chance for prolonged survival following splanchnicectomy. 
4. Of the patients still alive, 41 per cent of those with abnormal preoperative electrocardiograms recently showed significant improvement in their tracings five years or more after operation, and 44 per cent of those with preoperative cardiac enlargement recently showed significant decrease in heart size.

5. Practically all patients who have shown improvement in electrocardiogram or decrease in heart size have maintained a significant reduction in blool pressure.

6. Fifty per cent of hypertensive patients in whom an enlarged heart was demonstrated have not survived five to twelve years.

7. Splanchnic resection is of no avail in cases of marked cardiac enlargement with a variation greater than 50 per cent of predicted normal for frontal area or transverse diameter.

8. The patient with paroxysmal nocturnal dyspnea has little chance for. benefit from splanchnic resection; only 12.5 per cent survived five years or more.

9. Anginal seizures were frequently relieved following splanchnicectomy.

10. Of patients with gallop rhythm prior to operation, 23.3 per cent have survived five years or more.

11. The hypertensive patient in congestive heart failure which requires digitalization preparatory to splanchnicectomy stands one chance in three for prolonged survival following operation.

12. Eight out of eleven hypertensive patients who had had a coronary occlusion and were subsequently treated with splanchnic resection were still living five to nine years after operation.

Canabal and associates ${ }^{10}$ have recently supplied valuable information concerning the spontaneous evolution of the electrocardiogram in hypertension. They reported on a control series of fifty cases of hypertension with electrocardiograms taken over a period of five years or more. They found that in 10 per cent of the cases there was questionable-to-slight improvement of the electrocardiogram; that in 40 per cent, the tracings remained unchanged; and that in 50 per cent, they became worse. The spontaneous trend of the electrocardiogram in hypertension is to become worse as time goes on.

When one compares this control group with the eighty-three hypertensive patients who had abnormal electrocardiograms prior to splanchnic resection, and of whom 41 per cent showed significant improvement in their tracings five to twelve years later, and of whom only 3.6 per cent developed more serious electrocardiographic changes, then one may justifiably state that splanchnicectomy has beneficially influenced the destiny of the hypertensive patients with abnormal electrocardiograms who have been fortunate enough to have lived five years and longer after operation.

There were 127 hypertensive patients who showed no evidences of cardiac disease at the time of operation. Nine subsequentiy died, and eight, who were still living, have developed heart disease, confirmed by an abnormal electrocardiogram or cardiac enlargement by teleroentgenogram or by both. Of the 
hypertensive patients with normal hearts prior to operation, 86.6 per cent were living and had maintained a normal cardiac status for five to twelve years; 6.4 per cent were still living but had progressed to heart disease; and 7 per cent were dead. Has splanchnic resection significantly arrested progression to heart disease in hypertensive patients with normal hearts? Although the preceding figures appear appealingly good, no definite statement can as yet be made, for no appropriate control group is available for comparison.

Has splanchnic resection prolonged the lives of patients with hypertensive heart disease? Again no definite statement can be made even though the statistics of this series evoke a sympathetic response. The literature is inadequate concerning the life history of hypertensive patients with organic heart disease, and no fair comparisons can be made.

There are several reports in the literature on survival in hypertension, but in none are the hypertensive patients with heart disease separated from those with normal hearts. In Janeway's ${ }^{11}$ series of 458 hypertensive patients, onehalf of the men died within four years and one-half of the women within five years; by the tenth year, one-half of the remainder had died. Hamman ${ }^{12}$ had a 78 per cent mortality at the end of ten years. King and associates ${ }^{13}$ followed 481 patients for ten to sixteen years, and the mortality was 73 per cent. In onehalf of their cases, the discovery of hypertension was purely an incidental finding.

Wagener and Keith ${ }^{14}$ have presented a five-to-nine-year follow-up study of 219 cases of arterial hypertension, and they have offered the series as a control for any specific form of therapy. Their cases are classified according to retinal changes; the incidence of heart disease in this series is not known. One hundred forty-six of their patients had malignant hypertension. The remaining seventythree patients form a series comparable to the 384 paticnts presented in this paper. Of their hypertensive patients without papilledema, 24.6 per cent have survived five to nine years since the initial examination. Of the 384 hypertensives without papilledema in our series, 71 per cent have survived five to twelve years since operation. It appears that splanchnic resection may have beneficially influenced survival in hypertensive patients.

\section{SUMMARY}

This is a study of the cardiac aspects in 384 patients with arterial hypertension, treated surgically by the operation of bilateral supradiaphragmatic splanchnicectomy and lower dorsal sympathetic ganglionectomy. The findings suggest that this surgical treatment may have beneficially influenced the destiny of a significant percentage of hypertensive patients.

\section{REFERENCES}

1. Peet, M. M., and Isberg, E. M.: The Surgical Treatment of Arterial Hypertension, J. A. M. A. $130: 467,1946$.

2. Braden, S., and Kahn, E. A.: The Surgical Treatment of Hypertension: Preliminary Report, Yale J. Biol. \& Med. $11: 449,1939$. 
3. Peet, M. M., Woods, W. W., and Braden, S.: The Surgical Treatment of Hypertension, J. A. M. A. 115:1875, 1940.

4. White, P. D., Smithwick, R. H., Matthews, M. W., and Evans, E.: The Electrocardiogram in Hypertension. II. The Effect of Radical Lumbodorsal Sympathectomy, AM. HEART J. 30:165, 1945.

5. Bridges, W. C., Johnson, A. S., Smithwick, R. H., and White, P. D.: Electrocardiography in Hypertension. Study of Patients Subjected to Lumbodorsal Splanchnicectomv, J. A. M. A. $131 ; 1476,1946$.

6. Peet, M. M., and Isberg, E. M.: The Problem of Malignant Hypertension and Its Treat. ment by Splanchnic Resection, Ann. Int. Med. In press.

7. Hodges, P. C., and Eyster, J. A. E.: Estimation of Cardiac Area in Man, Am. J. Roentgenol. 12:252, 1924.

8. Hodges, F. J., and Eyster, J. A. E.: Estimation of Transverse Cardiac Diameter in Man, Arch. Int. Med. 37:707, 1926.

9. Goldring, W., and Chasis, H.: Hypertension and Hypertensive Disease, New York, 1944, Commonwealth Fund, Division of Publications.

10. Canabal, E. J., Warneford-Thomson, H. F., and White, P. D.: The Electrocardiogram in Hypertension. III. Electrocardiograms of Hypertensive Patients Followed for a Long Time Without Splanchnic Resection in Comparison With Those in Patients Who Had Had Splanchnic Resection, Am. HFaRT J. 30:189, 1945.

11. Janeway, T. C.: A Clinical Study of Hypertensive Cardiovascular Disease, Arch, Int. Med. 12:755, 1913.

12. Hamman, L.: Prognosis of Hypertension, Atlantic M. J. 31:472, 1928.

13. King, R. L., Carlile, T., and Blackford, J. M.: Hypertension: Follow-up Study of 481 Cases, Northwest Med. $41: 298,1942$.

14. Wagener, H. P., and Keith, N. M.: Diffuse Arteriolar Disease With Hypertension and the Associated Retinal Lesions, Medicine 18:317, 1939. 